\begin{tabular}{lllllllllllllllllllllllllllllllll}
\hline$R$ & $E$ & $V$ & I & S & T & A & D & E & E & S & T & U & D & I & O & S & I & N & T & E & $R$ & R & N & A & C & I & O & N & A & L & E & S
\end{tabular}

\title{
Desafíos y dilemas de seguridad en América Latina en la post Guerra Fría*
}

Gabriel Gaspar Tapia

¿Cuándo terminó la Guerra Fría en América Latina? ¿Fue un proceso homogéneo? ¿Cuáles son las necesidades que demanda hoy la realidad regional en materia de seguridad y defensa?

Este trabajo se orienta fundamentalmente por la última de las interrogantes enunciadas; pero ello requiere dar respuesta a las dos primeras, ya que indican el nivel histórico inmediatamente anterior en que nos situábamos como región.

\section{INTRODUCCIÓN}

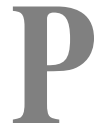

ara bien o para mal, el diseño de seguridad vigente durante la segunda mitad del siglo XX en América Latina estuvo enmarcado en la competencia por la hegemonía global que conocemos bajo el nombre de "Guerra Fría". Mucho se ha escrito sobre ello y también sobre el fin de dicha fase históri- ca. En términos casi universalmente aceptados, se entiende que la coyuntura que va desde la caída del Muro de Berlín (noviembre de 1989) hasta la disolución de la Unión Soviética y del Pacto de Varsovia (diciembre de 1991), que marca el fin de ese período.

En América Latina, el proceso global se acompaña de importantes sucesos en

* Este artículo forma parte de la obra "Cooperación y conflicto en las Américas. Seguridad hemisférica: un largo y sinuoso camino", Universidad Nacional Autónoma de México/Universidad Nacional de la Defensa de los Estados Unidos, México, 2003. Se publica en Estudios Internacionales con la autorización del autor. 
los diversos países de la región, acorde con las situaciones preexistentes, que reflejaban una variedad subregional significativa.

\section{A lo largo de los años ochenta se fue produciendo la transición de gobiernos militares a gobiernos civiles.}

En América Central tuvo lugar uno de los sucesos más importantes: el fin de las guerras que asolaron la región a lo largo de la década de los ochenta. En Nicaragua, las diversas fuerzas políticas lograron los denominados Acuerdos de Sapoá, que permitieron la configuración de un nuevo sistema que se estrenó con elecciones universales de las cuales surgió el gobierno de Violeta Barrios viuda de Chamorro, y el Frente Sandinista pasó a ocupar el rol de principal partido de oposición. En el caso de El Salvador, en enero de 1992, tras una exitosa mediación de las Naciones Unidas, se firmaron los Acuerdos de Chapultepec, que pusieron fin a la guerra civil. Lo mismo ocurre -tras idéntica mediación- en Guatemala, en diciembre de 1996.

En América del Sur, el proceso fue más político que militar. A lo largo de la década de los ochenta se fueron sucediendo las diversas transiciones de gobiernos militares o gobiernos civiles. La mayoría de los países ya habían recorrido los primeros pasos de este proceso en los años ochenta. A inicios de los noventa, con el fin de los gobiernos de los generales Pinochet y Stroessner, el panorama se completó.
En el Caribe, la situación tuvo sus principales expresiones en el fin de la dictadura haitiana en 1994 y el retorno del presidente Aristide. Asimismo, la subsistencia del régimen de partido único de Cuba constituye quizás uno de los últimos remanentes del período de enfrentamiento bipolar, expresado en especial en la continuidad conflictiva de las relaciones entre Cuba y los Estados Unidos.

México inició a fines de los ochenta, en especial luego de las repercusiones de las elecciones presidenciales de 1988, ocasión en que Cuahutémoc Cárdenas disputó cerradamente la nominación a Carlos Salinas de Gortari, un convulso proceso de reforma política que, poco más de una década más tarde, culminó, con el fin del largo dominio del PRI tras la victoria del presidente Vicente Fox en las elecciones del 2000.

No todas estas realidades estuvieron marcadas de igual manera por el escenario de la Guerra Fría, pero ninguna de ellas escapó completamente al panorama internacional; más aun en medio de una era en que la interdependencia se acrecentaba día a día. De partida, en todas ellas estuvieron presentes las peculiares condiciones que cada país, y de la región en su conjunto, mantenían con los Estados Unidos. De paso, no por sabido deja de ser importante que el papel de este país se modificó sustancialmente luego del derrumbe de su superpotencia rival.

Los tiempos de la Guerra Fría generaron un tipo de relación entre los Estados Unidos y los países de la región que, inevitablemente, colocaba los problemas de seguridad en la agenda hemisférica, 
pero muy influidos por la resonancia del en enfrentamiento bipolar. Muchos de los capítulos de esta relación tuvieron como rasgo común las diferentes ópticas con que se enfrentaron los problemas de seguridad. Para muestra, un botón: la crisis centroamericana para muchos fue el resultado de procesos internos originados en demandas de participación política y redistribución económica. Sin embargo, para la entonces administración de Ronald Reagan, las crisis de los países centroamericanos no eran más que el resultado del expansionismo soviético monitoreado desde La Habana. Por ello, aunque la política exterior del Departamento de Estado invariablemente reiteraba que su norte era la defensa de la democracia y los derechos humanos, en muchas oportunidades los Estados Unidos terminaban apoyando a sus diversos aliados locales, que generalmente coincidían con fuerzas que no eran democráticas ni practicantes del estado de derecho. Esta última circunstancia se reflejó con todo su dramatismo en el apoyo que el gobierno de los Estados Unidos brindó en la década de los setenta a las diversas dictaduras militares en América del Sur.

El escenario post Guerra Fría constituye un primer dato novedoso: los Estados Unidos pasaron a ser la potencia dominante no sólo en el hemisferio sino también a escala global. Y ese es un dato relevante. Si ya en tiempos de Guerra Fría los intereses en materia de seguridad de ese país eran a escala global -por ser una superpotencia- esto cobra mayor relevancia y dimensión en los nuevos tiempos, porque pasa a ser la única superpotencia.
Por tanto, aunque resulte obvio señalarlo, los intereses de seguridad de los Estados Unidos no se definen por su entorno inmediato o regional, sino que involucran su nueva posición en el sistema internacional en configuración.

\section{El papel de los Estados Unidos cambió sustancialmente tras el derrumbe de su superpotencia rival.}

El segundo dato, también resultante del escenario global de seguridad, lo dan los hechos del 11 de septiembre de 2001. Los atentados de Nueva York y Washington pusieron de relieve una nueva amenaza, tanto por su dimensión, como por los medios empleados y por los blancos elegidos. Constituyeron uno de los desafíos más grandes que conozcamos al poder de la nueva potencia y, al mismo tiempo, una reiteración de la brutalidad y del uso indiscriminado de la fuerza.

Entre el fin de la Guerra Fría y los atentados del 11 de septiembre transcurre una década de reacomodo del poder mundial. Este proceso está en pleno curso y en el futuro conoceremos su desenlace.

¿Qué ha pasado con América Latina en estos años? ¿Fue homogéneo este proceso para todos los rincones de nuestro continente?

Como señalamos en el breve recuento precedente, la región vivió intensos cambios en su realidad política, pero de naturaleza diversa. En algunas partes se vivieron procesos de pacificación que fueron de la mano de procesos de democratización; en otros, se transitó progresi- 
vamente a la civilidad. Pero el recuento es uno solo: a inicios de los noventa la generalización de formas democráticas predominaba en el debate y en la realidad. Se procede así, por razones diversas y propias, a una convergencia en la agenda: América Latina creó condiciones para desarrollar su democracia e insertarse en los nuevos tiempos de la economía globalizada.

\section{Parte importante de los problemas de seguridad regional tuvo como móvil los escenarios derivados del enfrentamiento bipolar.}

Sin embargo, una lectura de lo ocurrido en la región muestra que los "temas del pasado" no son tan extemporáneos, así como los nuevos tiempos no sólo han traído oportunidades sino también han generado escenarios de vulnerabilidades. En la década de los noventa tuvimos conflictos clásicos (Ecuador-Perú), sobrevivieron otros de larga data (Colombia), persistieron tensiones interestatales (Cuba-Estados Unidos) y se agregaron las nuevas vulnerabilidades surgidas de una vida más globalizada. Todo lo anterior nos habla de la existencia de una agenda más compleja en materia de seguridad y defensa, junto a la necesidad de poner al día los instrumentos y el debate, partimos de la base de que la Guerra Fría ha terminado.
I. LA CONVIVENCIA DE VARIAS AGENDAS

¿Se acabó la agenda tradicional?

Es común escuchar que la "agenda tradicional" ha sido superada por la aparición de una nueva agenda, propia de la era de la globalización y la interdependencia. En este tipo de afirmaciones, se subentiende que la "agenda tradicional" era aquella marcada por "amenazas tradicionales", las que se originaban preferentemente por conflictos interestatales. Hoy, en cambio, las principales amenazas serían de otra naturaleza.

Lo primero es atender a la afirmación primaria. ¿Era cierto que en la agenda tradicional los principales conflictos estaban dados por las hipótesis de conflicto entre Estados? Y, de ser así, ¿es cierto que hoy estas se ha reemplazado completamente por un nuevo tipo de conflictos?

La primera interrogante nos llevaría a un examen histórico que rebasa las modestas pretensiones de este artículo. Nos obligaría a examinar el acontecer en materia de seguridad que prevaleció en el hemisferio en la segunda mitad del siglo XX. Advirtiendo la provisionalidad de una hipótesis, lo que queremos dejar sentado es que en ese período estuvieron presentes sin lugar a dudas las tensiones originadas principalmente en la delimitación territorial (propias de la "agenda tradicional"), pero parte importante de la problemática de la seguridad regional tuvo como móvil los escenarios derivados del enfrentamiento bipolar, así como los distintos reacomodos nacionales para recomponer los pactos sociales vigentes. Y quizás fue 
este último tipo de conflictos el que predominó por encima de aquellos de la "agenda tradicional" que, en la jerga ideológica de la Guerra Fría, recibió el apelativo de "guerra interna".

\section{La mayoría de las tensiones han derivado a soluciones diplomáticas} o a la firma de acuerdos y tratados.

En efecto, en la segunda mitad del siglo XX estuvieron presentes las disputas territoriales, los acomodos de las relaciones interestatales y sus proyecciones geoestratégicas provenientes de tiempos pasados. En el Cono Sur, se expresó en la competencia entre Brasil y Argentina por la hegemonía en el Atlántico Sur y en las tensiones entre Argentina y Chile (con un clímax prebélico en 1978). La demanda argentina sobre las Malvinas llevó al conflicto de 1982 y su conocido desenlace. En la costa del Pacífico de América del Sur, Perú y Ecuador sostuvieron sucesivos enfrentamiento a lo largo del siglo XX: a los más severos de la década de los cuarenta se sumaron los incidentes de Paquisha y Falso Paquisha en los años ochenta (enero 1981). Por su parte, Perú no ha ocultado los preparativos que realizó en la década de los setenta contra Chile ${ }^{1}$ Venezuela y Colombia mantuvieron sus pretensiones sobre el Golfo de Maracaibo.
Asimismo, en América Central las tensiones entre El Salvador y Honduras (no necesariamente por disputas limítrofes) ocasionaron la denominada "guerra de fútbol" en los años setenta. Ambos países, más Nicaragua, sostienen una disputa por el Golfo de Fonseca. Colombia y Nicaragua mantienen diferencias sobre la delimitación marítima y algunas posesiones en islas del Caribe. A su vez, Nicaragua y Costa Rica tienen diferencias limítrofes sobre el río San Juan. Guatemala mantuvo un fuerte cuestionamiento al estatus de Belice.

¿Han desaparecido todas esas tensiones $^{2}$ ? Es indudable que una mirada global nos revata que afortunadamente la mayoría de ellas han derivado en gestiones diplomáticas o han sido superadas por la firma de acuerdos y tratados. También es manifiesto que hoy anualmente son de baja probabilidad en la mayoría de los análisis. Pero carecemos de elementos para afirmar que han sido definitivamente superadas: al menos en todos y cada uno de los casos mencionados.

Sin embargo, si se atiende a la historia reciente de la región, a su segunda mitad en el siglo pasado, se comprobara que buena parte de los conflictos armados (ya no sólo tensiones o hipótesis de conflicto) se originaron por razones internas, por efectos de la competencia bipolar o por movimientos hegemónicos de las potencias.

${ }^{1}$ En su momento, defendiéndose de una supuesta carrera armamentista contra Ecuador, el presidente Fujimori declaró que ella no era necesaria, porque su país se había armado pensando en un conflicto con Chile.

${ }^{2}$ La descripción presentada es sólo indicativa, hecha sólo a modo de ejemplo. Un recuento más amplio de las dificultades de origen "tradicional" es indudablemente materia que rebasa los límites del presente artículo. 
Si tomamos sólo el indicador de las bajas ocasionadas, o el número de efectivos empleados, o la duración del enfrentamiento, las guerras de Centroamérica de la década de los ochenta superan con creces a todos los conflictos de la historia de América Latina del siglo XX, salvo la cruenta revolución mexicana de 1910. En efecto, la guerra civil salvadoreña -por ejemplo- produjo miles de bajas, duró más de una década y empleó a decenas de miles de combatientes; en cambio, el conflicto que enfrentó a El Salvador con Honduras ("la guerra del fútbol”) fue de corta duración y ocasionó poquísimas bajas en comparación con la guerra civil. En suma, fueron los conflictos internos -no los de la "agenda tradicional"- los más cruentos de la historia reciente centroamericana. Sudamérica también refleja esta misma tendencia. Tomemos al respecto un par de datos: en la guerra de las Malvinas, las bajas argentinas fueron ampliamente superadas por eso que provocó la llamada "guerra sucia" que desencadenó la dictadura en dicho país ${ }^{3}$. El número de bajas y el período de duración del último enfrentamiento entre Ecuador y Perú en la Cordillera del Cóndor, fueron incomparablemente menores a los miles de muertos que ocasionó el enfrentamiento entre el Estado peruano y Sendero Luminoso ${ }^{4}$.

Por su parte, salvo la notable excepción de Costa Rica, la violencia política se manifestó en conflictos internos de diversa índole en la totalidad de los países latinoamericanos. Al respecto, cabe señalar la emergencia de movimientos insurreccionales que asumieron diversas formas de lucha irregular, las que fueron debidamente replicadas por las fuerzas armadas, ocasionándose no sólo procesos de conmoción política, sino guerras civiles declaradas 5 ; todo ello, en el marco estratégico bipolar de la Guerra Fría.

\section{La violencia política se manifestó en conflictos internos de diversa índole.}

En suma, en el pasado reciente, no siempre fue "la agenda tradicional" la que hegemonizó la problemática de seguridad de nuestra región. En realidad, mayor incidencia tuvieron los conflictos derivados de la Guerra Fría y de las disputas internas por reorganizar los pactos sociales.

Por su parte, las invasiones de los Estados Unidos a Santo Domingo (1964), a Granada (octubre 1983), a Panamá (diciembre de 1989, se explican más por la

${ }^{3}$ En efecto, las bajas argentinas en Malvinas bordearon el millar de muertos en acción. En cambio, sólo el número de secuestrados y desaparecidos por los servicios de seguridad durante la dictadura supera varias veces esa cifra.

${ }^{4}$ En la guerra con Ecuador, las bajas peruanas no pasaron de unos pocos centenares; en cambio, en el enfrentamiento con la insurgencia maoísta las estimaciones ascienden a mas de 15.000 , la mayoría víctimas civiles. En cuanto a duración la guerra con Ecuador, esta se prolongó del 22 de enero al 23 de febrero de 1995. En cambio, la guerra interna se inició en 1980 y duró hasta 1992 (detención de Abimael Guzmán), aunque restos de la guerrilla senderista perduran hasta hoy.

${ }^{5}$ La variedad y complejidad de este tema fueron desarrollados más ampliamente por este autor en "Guerrillas en América Latina", Flacso, Chile, 1997. 
lógica de los intereses hegemónicos de la potencia que por razones "tradicionales" (conflictos interestatales).

En suma, no existe evidencia histórica que permita afirmar que los conflictos "tradicionales" han sido superados, ni tampoco que ellos sólo se explican por problemas de delimitación fronteriza entre los diversos Estados. Todo lo anterior no obsta para que en tiempos de la post Guerra Fría haya mejores condiciones para que las probabilidades de este tipo de conflictos sean menores.

\section{La agenda de cooperación}

Sin embargo, es a todas luces evidente que en los últimos años estamos en presencia de un nuevo fenómeno: la emergencia de una agenda de cooperación entre la mayoría de los Estados de nuestra región.

En efecto, si se tiene en cuenta la proliferación de medidas de confianza mutua en la zona se verá que se trata de un fenómeno nuevo en la región: virtualmente no hay países de América Latina que en los últimos años no hayan suscrito algún tipo de acuerdo de esta naturaleza con uno o más países vecinos.

Este proceso se da de la mano de otro en la esfera económica: el incremento de acuerdos de complementación económica, la apertura comercial y, en varios casos, la suscripción de acuerdos de libre comercio. Estamos en presencia de una segunda oleada de integración regional, la cual muestra notorias diferencias respecto de la que conociéramos en la década de los setenta. En aquella oportunidad, la integración tenía más bien connotaciones defensivas respecto del mercado mundial, implicaba una percepción de amenaza de la presencia de las economías foráneas (en especial a las potencias) y, por lo mismo, se fomentaban modelos de "sustitución de importaciones". La ALALC fue buen reflejo de este tipo de integración -que explica en gran medida sus limitaciones- y el Pacto Andino constituyó uno de sus ejemplos más avanzados.

\section{La integración va de la mano con el deseo común de nuestros países de incorporarse al proceso de globalización.}

Sin embargo, actualmente se vive otra situación, tanto de la historia como de la evolución económica. La integración que hoy se observa va de la mano del común deseo de los países de nuestra región de incorporarse sin cortapisas al proceso de globalización. El supuesto estratégico no es más que el entender que, dadas las dimensiones de este proceso y sus consecuencias, "a la globalización es mejor entrarle asociados", que inunda a muchas de las actuales elites latinoamericanas.

\section{LOS PROBLEMAS}

\section{a) Extensión del concepto de seguridad}

Hoy en día, el tema de la seguridad, se ha tornado mucho más complejo debido a dos grandes razones: la diversifica- 
ción de los actores y de los temas de la agenda. Todo ello, por cierto, en el contexto de la recomposición de hegemonías a escala global.

La emergencia de nuevos actores internacionales es un tema bastamente conocido y analizado: actualmente, además de los Estados Nación, emergen como nuevos actores internacionales diversos organismos internacionales, empresas multinacionales, organizaciones no gubernamentales de envergadura y de creciente concertación a escala global y regional, por nombrar algunos de los principales nuevos actores que hoy pueblan y densifican la comunidad internacional. Este proceso también se expresa en nuestra región: desde los organismos de coordinación política (OEA, Grupo de Río) hasta los organismos de integración económica que asumen crecientes cuotas de politización (Mercosur, Comunidad Andina), a todo lo cual hay que agregar la emergencia de una atiborrada de diplomacia de Cumbres: a las Cumbres Hemisféricas (todos menos Fidel), Cumbres Iberoamericanas (con Rey, sin Bush y con Fidel), recientemente se han agregado las Cumbres Sudamericanas.

En estos años también se han diferenciado los temas de seguridad en la región. En efecto, como ya se ha señalado en diversas oportunidades, en la época de la post Guerra Fría, las diversas subregiones de América Latina muestran dife- rentes énfasis en sus preocupaciones de seguridad. Si las diferenciamos en términos geográficos, tenemos a lo menos cuatro: Cono Sur, macizo andino, istmo centroamericano y Caribe.

\section{La región del Cono Sur es quizás donde se hacen sentir con más fuerza los nuevos enfoques de la seguridad.}

A grandes pinceladas, podemos decir que la región del Cono Sur (que tiende a coincidir mucho con el ámbito del Mercosur $\left.{ }^{6}\right)$, es quizás donde se hacen sentir con mayor fuerza los nuevos enfoques de la seguridad. Es la zona donde los temas de la "agenda tradicional" han quedado más claramente subordinados a los nuevos temas de una agencia de cooperación e integración. Es, por lo mismo, un área en la cual las medidas de confianza mutua han avanzado hacia mayores niveles de profundidad: pilotos navales argentinos entrenan en portaaviones brasileños y el buque insignia argentino se repara en astilleros chilenos. Tropas argentinas, uruguayas, brasileñas, bolivianas y chilenas participan cada vez con mayor presencia en misiones de paz de Naciones Unidas.

Por cierto, no es ajeno a esta realidad el que la mayoría de los países integrantes de esta subregión han asumido políticas exteriores de inserción a las nuevas

${ }^{6}$ La diferencia es señalada por Brasil. La potencia sudamericana es indudablemente parte del Cono Sur, pero también es un país amazónico (el principal) y asimismo un país de proyección oceánica. A ello suma su presencia en la comunidad lusoparlante y su innegable aspiración a ser potencia global, o al menos, a participar sustantivamente de la agenda planetaria. Por lo demás, Brasil colinda con todos los países sudamericanos, excepto Chile. 
realidades de la economía global. Al mismo tiempo, los dos países principales, Brasil y Argentina, han diseñado estrategias nacionales de creciente integración en materia económica. El Mercosur es un ámbito indispensable en el análisis latinoamericano: concentra más de la mitad del producto interno de la región, buena parte de su producción industrial y agrupa a la mitad de la población de América Latina; lleva ya una década de vida, con altibajos en su balance. Si bien en el ámbito económico las vicisitudes de las economías nacionales integrantes de este acuerdo han limitado los resultados deseados, no ocurre lo mismo en el ámbito político. En este plano, los logros de concertación son evidentes, al punto de que a estas alturas se ha convertido en un referente obligado al hablar de la región. Así, el "Mercosur político" muestra más logros que el "Mercosur económico" y ello se expresa en los temas de la seguridad.

Los países integrantes del macizo andino viven una realidad de seguridad que tiene su epicentro en una compleja trilogía: narcotráfico, guerrillas e inestabilidad política. Estos tres ingredientes están presentes en diversas intensidades en los países del litoral caribeño y del Pacífico norte de Sudamérica. Estas realidades internas obviamente repercuten en las necesidades y prioridades que cada uno de ellos brinda a su seguridad: militarización de fronteras, incremento de controles de espacios aéreos y marítimos requerimientos específicos de equipamiento, relación especial con los Estados Unidos, cuidadosa relación entre la clase política y las Fuerzas Armadas, por señalar algunas áreas.

\section{La realidad de seguridad de los países andinos tiene su epicentro en la trilogía narcotráfico-guerrillas- inestabilidad política.}

Este subregión tiende a coincidir en sus delimitaciones con lo que fue en sus inicios la Gran Colombia. En el ámbito económico, se expresa en lo que hoy es la Comunidad Andina de Naciones $(\mathrm{CAN})^{7}$. En esta región, los temas de la agenda anterior están más presentes que en el Cono Sur. Los conflictos territoriales mantienen cierta vigencia, como se expresó en la denominada guerra de la Cordillera del Cóndor, entre Ecuador y Perú; al mismo tiempo, las guerrillas son una realidad (aunque de diferente dimensión) en Colombia y Perú. Es decir, los temas de la "agenda tradicional", amen de las herencias deformadas de la Guerra Fría, están presentes en el macizo andi-

\footnotetext{
${ }^{7} \mathrm{La}$ asociación no es rotunda.

${ }^{8}$ Recordemos, además, que, en sus mejores momentos, Alberto Fijimori reconoció que el Perú había realizado numerosas adquisiciones militares pensando en un conflicto con Chile. Más recientemente, el Congreso peruano emplazó al Ministro de Defensa sobre la filtración de documentos que señalaban que Ecuador y Perú constituían amenazas a la seguridad nacional. Estos hechos fueron recogidos por el Correo de Lima en su versión del 28 de octubre del 2002, según la cual "Chile aspira a ocupar un posicionamiento bélico de vanguardia en el ámbito regional y Sur Pacífico" que lo convertiría en "la primera amenaza de carácter externo para el Perú".
} 
no. Además, la democracia y su profundidad han sido puestas a prueba en más de una ocasión, lo que explica que en esta zona es donde la presencia política de las Fuerzas Armadas sea aún un tema de la contingencia. En suma, es posible afirmar que, en la costa atlántica, la nueva agenda de cooperación tiene una mayor velocidad que en la del Pacífico. Un capítulo especial en materia de seguridad lo es el problema del narcotráfico, las dimensiones que ha alcanzado, su capacidad de reconversión (hemos pasado de los grandes carteles de los ochenta a una proliferación de organizaciones y a su entrelazamiento con la violencia política). En esta región es quizás donde, por su dimensión y contexto, el problema del narcotráfico involucra el empleo de la fuerza armada, a diferencia de la mayoría de los países en los cuales el tema cabe dentro de la competencia policial y, a lo sumo, de coordinación de inteligencia.

\section{En la costa atlántica la nueva agenda de cooperación tiene mayor velocidad que en la del Pacífico.}

Los países de Centroamérica viven en los tiempos de la post Guerra Fría una nueva realidad, porque son también los tiempos de la pacificación y la democratización. Sus sistemas políticos sufrieron un punto de inflexión con el fin de las diversas guerras civiles que los asolaron en la década de los ochenta. Profundización democrática, desarme de los grupos alzados en armas, reinserción de los ex combatientes a la vida civil, politización de las antiguas guerrillas, disolución de los antiguos servicios de seguridad. Con niveles diferentes de éxito, los países del istmo centroamericano avanzan en un contexto de democratización y apertura económica, como también de creciente concertación para su inserción internacional.

De esta manera, la diversificación de actores y la variedad de problemáticas de seguridad en la región es un hecho notable de los año noventa en adelante. A ello hay que agregar otro elemento: los diversos enfoques al tema de la seguridad que emergen en estos años. En efecto, en este período han surgido las propuestas de la denominada seguridad humana, que proclama una mayor atención a los temas que emergen de la seguridad de las personas, además de la clásica preocupación de los Estados en esta perspectiva, temas tales como la defensa de los derechos humanos, la garantía del ejercicio efectivo de los principales derechos sociales, la preocupación por enfermedades endémicas y la necesaria concertación internacional para combatirlas, entre otras, debieran ser parte de la nueva agenda.

Estas propuestas están en una etapa de desarrollo y aún no se implantan ni tampoco se configuran en una proposición acabada, al menos en lo que se refiere al ámbito de la seguridad regional o hemisférica. Abren varias interrogantes que es necesario abordar desde un punto de vista académico.

En primer término, la pertinencia del concepto. Si el sistema internacional se basa en la concepción de comunidad de Estados naciones y las organizaciones 
multilaterales que ellos acuerden junto con su correspondiente normativa, cabe preguntarse cómo se puede articular una concepción que vele por el cabal cumplimiento de políticas públicas específicas, sin con ello afectar la forma soberana en que una comunidad nacional determinada haya resuelto enfrentar esa tarea. Si se entiende que todo Estado asume compromisos, como los deberes y derechos que consagra la Carta de las Naciones Unidas, y la forma de enfrentarlos estará a cargo de los gobiernos, los cuales diseñarán las correspondientes políticas públicas, entonces una concepción amplia de seguridad podría colisionar con estos fundamentos. A menos que se considere que algunos Estados no estarían en condiciones de llevar adelante sus compromisos. Una respuesta clásica y realista indica que ello es más que posible, pero también sugeriría que, para resolver esas insuficiencias, está el camino de la cooperación internacional. Es decir, los convenios bilaterales o multilaterales a través de los cuales un país determinado solicita apoyo para enfrentar una determinada tarea a otros.

En una versión más tajante del realismo, también se asumiría que los Estados tienen objetivos y éticas que involucran su propia supervivencia, donde obviamente están involucrados los elementos que les dan vida: población y territorio entre los principales. Por tanto, la forma como un Estado determinado cautele los intereses de su población dependerá de la soberanía efectiva de ese Estado, y sus autoridades (encargadas de esa soberanía) surgirán del mecanismo que cada comunidad nacional adopte para ello.

\section{Los Estados tienen objetivos y éticas que involucran su propia supervivencia.}

Existe otra secuela de estas concepciones "amplias" de seguridad, como la que nos produce la seguridad humana. $\mathrm{Al}$ extender el concepto de seguridad más allá de los clásicos elementos de la seguridad entre los Estados y la procura de la paz entre ellos, se abre un abanico de problemáticas: ¿hasta dónde llegan los ámbitos de seguridad sobre los cuales debe de pronunciarse un Estado? Si los derechos humanos, la protección del medio ambiente, el sida y otras enfermedades endémicas deber ser materia de seguridad, ¿no estamos quizás volviendo a las concepciones totalizadoras de la seguridad? En un pasado reciente, los latinoamericanos conocimos otra concepción sobre la seguridad: la denominada seguridad nacional, comprendida en los términos de la Guerra Fría y con un particular énfasis en la contrainsurgencia y el combate al "enemigo interno". En esta versión, el "enemigo" se infiltraba en la sociedad y, desde su interior, iniciaba su labor de zapa; por ello, había que inocular en muchos ámbitos. Así, desde la malla curricular de las carreras de ciencias sociales hasta la censura cinematográfica, pasando en los ratos de mayor entusiasmo por la censura a canciones y autores, tuvimos presente una "seguritización" de la sociedad en sus más diversos ámbitos.

En el ámbito de la Defensa, el tema está precisado: los temas de la seguridad 
que involucran al sector defensa son aquellos que conllevan el uso de la fuerza, la utilización de este recurso privativo de los Estados.

\section{b) La coexistencia en el continente de potencias junto a países de diferente estatura estratégica}

América es un continente asimétrico. En casi todas las variables encontraremos una marcada diferencia entre el potencial de los Estados Unidos y el resto de los países, inclusive entre ellos. Si medimos potencial económico, capacidad de producción industrial y desarrollo tecnológico, niveles de escolaridad, potencial diplomático, entre otros, encontraremos esa diferencia que, por cierto, se refleja en materia estratégica.

Se puede argumentar que esta realidad siempre ha existido ${ }^{9}$, pero en los últimos años, la asimetría tanto en materia económica como estratégica se ha acentuado. Considerando el producto interno bruto, encontramos una marcada diferencia entre lo que los Estados Unidos (y América del Norte en general), respecto de América Latina y el Caribe. El siguiente cuadro (construido con datos del Banco Mundial) nos muestra la diferencia existente entre la economía estadounidense y algunos de los países de América Latina.

\section{PRODUCTO NACIONAL BRUTO}

AÑO 2000

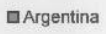

aBolivia

口Brasil

口Chile

aPerú

口México

aCanada

DEE.UU.

Esta notable asimetría obviamente se expresa en una diversidad de intereses de los Estados en el ámbito internacional y, por ende, en sus agendas de seguridad y defensa.

Desde que los Estados Unidos completaron su unificación territorial alcanzando la costa del Pacífico y resuelta la Guerra de Secesión, su proyección geopolítica se hizo patente en la cuenca del Caribe y en sus relaciones con México y Centroamérica. En ese período los países sudamericanos, en mayor o menor medida, mantuvieron diversos entendimientos con las potencias europeas de la época; sin embargo, tras el desenlace de las dos guerras mundiales y la pérdida de poder de las potencias europeas, su peso estratégico, unido a la influencia política y económica del país penetró a profundidad en las naciones sudamericanas. Desde el punto de vista de los mecanismos

${ }^{9}$ Lo de "siempre" es relativo. Sería interesante comparar cómo se fue acentuando esta brecha económica y tecnológica. Para muestra, dos botones. A fines del siglo XIX, Chile poseía quizás una de las flotas más modernas y poderosa de la época, que le proporcionaba un potencial en el Pacífico difícil de igualar. En los años de oro de la economía argentina (los primeros del siglo XX), sería interesante comparar su potencial con el de los Estados Unidos. Al menos era claro que era superior al de los países mediterráneos, por algo se explica la emigración de aquellos años. 
de seguridad, esto se tradujo en la firma del Tratado de Río (que consagró el TIAR) y el establecimiento de un vasto programa de colaboración bilateral (los denominados PAM, o Pactos de Ayuda Militar) entre los Estados Unidos y la mayoría de los países latinoamericanos. Una de las constantes del accionar estadounidense ha sido evitar la presencia de otras potencias en la región. En tiempos pretéritos, este factor dio origen a la doctrina Monroe; la época de la Guerra Fría se expresó en la preocupación por que un país cayese "en la órbita soviética". Las bases militares en Cuba, el apoyo material a los sandinistas en Nicaragua, fueron motivo de preocupación para el Pentágono. Pero la presencia rusa logró clavar otra cabeza de playa: la venta de armamento a Perú, fenómeno que ha sobrevivido el fin de la Guerra Fría y conserva plena vigencia en nuestros días.

\section{Una constante del accionar estadounidense ha sido evitar la presencia de otras potencias en la región.}

Si en tiempos de la Guerra Fría el peso de la potencia estadounidense era inocultable, en los días posteriores al fin del enfrentamiento bipolar ha aumentado aún más. Hoy en día, como lo recordáramos anteriormente, Estados Unidos es la única superpotencia del globo y, por ende, sus intereses de seguridad están concebidos a escala global, planetaria. América Latina es parte de sus intereses, y no siempre será parte más prioritaria. En suma, en el hemisferio tenemos la presencia de la principal potencia del orbe.

En menor medida, Canadá también representa al sector del continente que está preocupado más allá de los límites continentales. Forma parte de la OTAN y del Grupo de los Siete. Su diseño de seguridad, al igual que el de los Estados Unidos, está proyectado más allá del ámbito continental.

A escala regional, en el continente hay dos países que poseen clara proyección regional: México y Brasil. Tanto por su masa demográfica como por el tamaño de sus economías, ambos ejercen una innegable influencia en su entorno. Asimismo, son poseedores de una tradición diplomática rigurosa: Tlatelolco e Itamaratí son dos de las principales y más experimentadas Cancillerías latinoamericanas. En materia estratégica, tienen algunas diferencias entre sí: mientras Brasil se ha esforzado por preservar un potencial estratégico acorde a sus pretensiones de participación en los asuntos globales y regionales ${ }^{10}$, México padeció en las últimas décadas del siglo pasado de un progresivo empequeñecimiento de su potencial militar. Este proceso sólo fue revertido parcialmente con ocasión del levantamiento de Chiapas, que se tradujo en un aumento de efectivos, equipos y capital político del ejército mexicano.

${ }^{10}$ Brasil es hoy el único país latinoamericano que posee portaaviones, una industria de defensa activa y está presente en el mercado mundial de armas. Tiene proyectado, además, una importante renovación de su flota aérea. 
A continuación, encontramos una diversidad de casos nacionales, pero la mayoría de ellos están definidos en materia de seguridad por intereses localizados principalmente en su entorno vecinal. Además en la región hay varios países de economías pequeñas, cuyas problemáticas de seguridad tiene poco que ver con la defensa clásica, al punto de que muchos de ellos carecen de fuerzas armadas (como es el caso de la mayoría de los países del Caribe).

Como ya dijimos, esta variedad de estaturas estratégicas del mosaico americano no es nueva, pero se ha acentuado en los últimos años. Cabe preguntarse si la diversidad en materia de intereses de seguridad permite construir un sistema de seguridad hemisférico basado en una amenaza común y ¿cuál sería esta en tiempos de post Guerra Fría?

\section{EL PROBLEMA}

DE LA INSTITUCIONALIDAD

La seguridad hemisférica tuvo un punto de inflexión al finalizar la Segunda Guerra Mundial. A la sazón se estructuraron dos acuerdos multilaterales que dieron forma a un mecanismo diplomático, la Organización de los Estados Americanos (OEA) y uno de seguridad, el Tratado Interamericano de Asistencia Recíproca (TIAR). Ambas iniciativas consagraron los principios del panamericanismo; es decir, concibieron a toda la región con intereses compartidos.

\section{La OEA y el TIAR consagraron los principios del panamericanismo.}

Históricamente, este principio (una de las bases de la denominada doctrina Monroe) fue resistido por los principales países sudamericanos, que desconfiaron de la presencia de los Estados Unidos en la región. En su momento, se apoyaron indistintamente en las diversas potencias europeas, tanto en materia de inversiones, como de asistencia militar y apoyo diplomático. México, por su parte, siempre ha tenido que desarrollar una compleja estrategia diplomática que combine el hecho de la cercanía con los Estados Unidos y lo cautele de ella.

El desenlace de la Segunda Guerra Mundial afectó una de las bases de la estrategia de los países reticentes al panamericanismo. El debilitamiento de las potencias europeas junto a la transformación de los Estados Unidos en superpotencia, unido al nuevo escenario de la Guerra Fría, generó un cuadro en el cual no fue posible oponer resistencia al panamericanismo. Así, nacieron las dos organizaciones que hoy cautelan el ámbito diplomático y el de seguridad en el continente: la OEA y el TIAR.

Aunque no es el motivo de este trabajo, ni tenemos oportunidad por lo mismo de desarrollarlo, queremos constatar como elemento contextual que ambos organismo estuvieron marcados por el clima y la visión de la Guerra Fría. Su gestión inicial al menos lo confirma: la OEA debutó apoyando la invasión que 
derrocó el gobierno del presidente Jacobo Arbenz en Guatemala, en 1954, y con posterioridad expulso a Cuba de la Organización, entre otras actuaciones. Con la misma rigurosidad, habría que constatar que en los últimos años ha hecho gran hincapié en la defensa y promoción de los derechos humanos y en la democracia. El TIAR tuvo su prueba de fuego con la guerra de las Malvinas; allí, los Estados Unidos estuvieron en un dilema fatal: tuvieron que optar entre su alianza atlántica y su alianza hemisférica. Obviamente, optaron por la más importante para sus intereses nacionales, pero ello le acarreó una sombra de desconfianza en vastos sectores, que perdura hasta la fecha ${ }^{11}$.

Por todo lo anterior, el tema de la institucionalidad de la seguridad no es menor en este debate. Es lo que queremos analizar a continuación.

\section{a) Las limitaciones del sistema formalmente vigente y la emergencia de la arquitectura flexible}

Si hay algo que quedaba claro al finalizar el siglo XX es que el sistema de seguridad imperante en el hemisferio americano no respondía a las nuevas necesidades. Tampoco queda claro que haya servido mucho en tiempos de Guerra Fría.

Esto es una paradoja, dado que el sistema de seguridad consagrado por el Tratado Interamericano de Asistencia Recíproca (TIAR) no estuvo presente en la prevención ni en la solución de ninguno de los conflictos armados que se suscitaron en la región en las últimas décadas del pasado siglo. Como se ha señalado en diversas oportunidades, si examinamos la historia militar latinoamericana tenemos lo siguiente en las últimas décadas

\section{Conflictos armados en la región} y mecanismos de solución ${ }^{12}$

\begin{tabular}{|l|l|}
\hline Guerra de las Malvinas & Solución militar \\
\hline Guerra Ecuador-Perú & Intervención Países Garantes \\
\hline Guerra civil salvadoreña & $\begin{array}{l}\text { Solución política con mediación Naciones } \\
\text { Unidas }\end{array}$ \\
\hline Guerra civil guatemalteca & $\begin{array}{l}\text { Solución política con mediación Naciones } \\
\text { Unidas }\end{array}$ \\
\hline Guerra civil nicaragüense & Solución política - Acuerdos Sapoá \\
\hline Invasión Estados Unidos a Panamá & Solución militar \\
\hline Invasión Estados Unidos a Granada & Solución militar \\
\hline Invasión Haití & $\begin{array}{l}\text { Solución militar al amparo Resolución } \\
\text { Naciones Unidas }\end{array}$ \\
\hline Insurgencia Sendero Luminoso & Solución político - militar interna \\
\hline
\end{tabular}

En suma, la historia reciente de la región nos muestra dos cosas:

En primer lugar, la inoperancia de la institucionalidad consagrada en el TIAR. Más allá de las valoraciones de a cual-

${ }^{11}$ Como se recordará, el gobierno de los Estados Unidos hizo desesperados esfuerzos de mediación entre Inglaterra y Argentina, pero las posiciones irreductibles de la Thatcher y del general Galtieri los hicieron imposibles; desencadenadas las acciones militares, los Estados Unidos apoyaron con todo a su principal aliado global. La desconfianza que esta actitud generó en los círculos nacionalistas y castrenses de la región ha tenido un largo efecto.

${ }^{12}$ Se consideran conflictos de las dos últimas décadas del siglo XX. 
quier índole que nos motive el TIAR, lo cierto es que el citado mecanismo no estuvo presente en ninguno de los principales conflictos armados de la historia reciente de nuestra región. En segundo término y quizás motivado por la primera constatación, en la mayoría de estos casos surgieron diversos mecanismos ad hoc que suplieron esa ausencia. En el caso de las guerras centroamericanas surgieron, primero, el denominado Grupo de Contadora, y posteriormente los Acuerdos de Esquipulas. El primero lo formaron México, Venezuela, Panamá y Colombia (los países fronterizos de Centroamérica), que constituyeron un grupo facilitador de las negociaciones políticas. $\mathrm{Su}$ contundencia fue tal que, luego de ampliarse a otros países sudamericanos, terminó dando origen al actual Grupo de Río ${ }^{13}$, principal referente de concertación política latinoamericana. Por su parte, el Acuerdo de Esquipulas, constituido por cinco países centroamericanos y Panamá, sentó sustantivas bases en la segunda mitad de la década de los ochenta del siglo pasado, para abrir paso a soluciones negociadas a nivel político a los diversos conflictos del istmo centroamericano.

Asimismo, en la década de los noventa se puso en movimiento un diversificado proceso de construcción de confianza mutua entre los diversos países de la región. Los acuerdos de esta naturaleza, esencialmente referidos a los temas militares, han alcanzado diversos niveles de profundidad. En algunos casos se ha superado el primer nivel de confianza (información oportuna y medidas protocolares) para pasar a una segunda y, en algunos casos, una tercera generación de medidas, como las ya señaladas entre Brasil y Argentina (instrucción de pilotos argentinos en portaaviones brasileño) o las que se desarrollan entre Argentina y Chile (como la reparación de buques de guerra argentinos en astilleros chilenos). Las medidas de confianza mutua, la verdadera red que han construido, no constituyen un sistema organizado de seguridad regional, dado su carácter esencialmente bilateral, pero sin lugar a dudas que contribuyen poderosamente a crear un entorno de confianza y, por ende, de estabilidad y transparencia en la región.

\section{Las resoluciones de los organismos subregionales han reabasado lo económico-comercial para incluir acuerdos políticos que inciden en el ámbito de la seguridad.}

Por su parte, los organismos de integración subregional (como Mercosur, la comunidad Andina de Naciones, el

${ }^{13}$ Como es sabido, el Grupo de Río es el principal foro de concertación política del bloque de países latinoamericanos. En él sólo participan países al sur del Río Bravo y marca notoria diferencia con la Organización de Estados Americanos. Se coordina mediante una Secretaría Pro Tempore rotativa y ha logrado establecer diálogos con los países de Europa y Asia. Su mecanismo ágil y no burocrático descansa en gran medida en la voluntad política de sus integrantes que practican una diplomacia directa sin conformar un nuevo elefante multilateral. 
Acuerdo Centroamericano) han aprobado resoluciones que van más allá de lo estrictamente económico-comercial y han establecido acuerdos políticos que inciden directamente en ámbitos de seguridad. Así, el Mercosur ha establecido una zona de paz en sus límites y ha consagrado una denominada "cláusula democrática", que involucra un compromiso regional en torno a los valores de la paz y la democracia en la región. Acuerdos similares podemos encontrar en los otros pactos subregionales.

Y, finalmente, también encontramos mecanismos ad hoc, diseñados para enfrentar conflictos específicos, como el denominado Protocolo de Río, que establece un grupo de países garantes destinados a cautelar las tensiones entre Ecuador y Perú y, dado el caso, mediar entre las partes. Este mecanismo funcionó con eficacia en el conflicto de 1995 y en su posterior solución diplomática.

Cabe destacar, con la misma fuerza, que las debilidades de los mecanismos interamericanos para buscar soluciones políticas o diplomáticas a los conflictos han sido suplidas por la actividad y la presencia del consejo de Seguridad de las Naciones Unidas en varios de estos mismos conflictos: Salvador, Guatemala, Haití, entre otras, son experiencias que revelan esta tendencia.

Resumiendo, a partir de los últimos años del siglo XX se fue articulando un conjunto de mecanismos heterogéneos y diversos que coinciden en el propósito de crear mejores condiciones de seguridad y estabilidad en la región; inclusive, que han sido capaces de resolver los princi- pales conflictos armados que se han suscitado en estos años. Surgimiento de grupos de países "amigos", consolidación de estructuras subregionales de seguridad, proliferación de medidas de confianza mutua, eficaz complementación y cooperación con el Consejo de seguridad de las Naciones Unidas, son, entre otros, los principales mecanismos. Todos ellos forman lo que se ha denominado una "arquitectura flexible" de seguridad emergente en la región.

\section{Los mecanismos de seguridad surgidos en la región han configurado una "arquitectura flexible".}

Esta arquitectura se caracterizaría entre otros aspectos por los siguientes rasgos:

a) En primer lugar, porque la mayoría de estos nuevos mecanismos poseen un marcado énfasis subregional. Desde la experiencia inicial del Grupo Contadora hasta la intervención de los países garantes en el conflicto entre Ecuador y Perú, lo característico es que se trata de mecanismos surgidos atendiendo a la naturaleza particular del conflicto, y no la aplicación de un régimen jurídico de mediación preestablecido. Asimismo, ese carácter local permitió que estos mecanismos, y puede permitirle a futuros homólogos, atender a la peculiaridad geopolítica localizada que se reflejaba en dichos conflictos. Es por ello que muchos observadores ligan esta cualidad al reconocimiento de que hoy en día el conti- 
nente tiene diferentes realidades subregionales en materia de seguridad ${ }^{14}$.

b) En segundo término, resalta el carácter ágil y ejecutivo de estos mecanismos, al no apoyarse en burocracias preestablecidas. A diferencia de los mecanismos vigentes de carácter interamericano (TIAR, Junta Interamericana de Defensa), se trata de mecanismos de diálogo político a alto nivel, estructurados a partir de fórmulas de diplomacia directa, muchas veces mediante la presencia de representantes de primer nivel de las Cancillerías involucradas, cuando no de los Jefes de Estado directamente (como fue el caso de los Acuerdos de Paz de Esquipulas, en Centroamérica).

\section{La mayoría de los acuerdos estuvo apoyada por países mediadores o facilitadores.}

c) Asimismo, la mayoría de estos mecanismos estuvo apoyada por la presencia de un grupo de países mediadores o facilitadores (que habitualmente reciben el nombre de "países amigos"). Cabe destacar que en este proceso el Consejo de Seguridad de las Naciones Unidas ha cumplido un importante rol articulador de estas fórmulas y dinamizador de sus gestiones ${ }^{15}$. El papel de Álvaro de Soto en las negociaciones salvadoreñas, así como el desempeño de los mediadores que ONU designó para las negociaciones guatemaltecas, fue particularmente destacado y reconocido por las propias partes en conflicto. Contrasta en todos esos casos con la actuación del organismo diplomático hemisférico: la Organización de los Estados Americanos.

d) Finalmente, es destacable el carácter ad hoc de muchos de estos mecanismos. Resuelto el conflicto, constituidos sus mecanismos de verificación y control, cumplido el cronograma de pacificación, se retorna al normal funcionamiento diplomático a través de las Cancillerías. Cuidado, esto no quiere decir que estos mecanismos sean ajenos a las diplomacias regulares; por el contrario, surgen de ellas y de la voluntad política de las jefaturas de Estado. Lo que queremos destacar es que cumplida la misión pacificadora propuesta, no se sedimenta ninguna organización temporal, evitando con ello aumentar la ya frondosa (y además costosa) burocracia internacional.

Estos rasgos de ejecutividad y efectividad han sido las mejores cartas de presentación de esta "institucionalidad emergente" en materia de seguridad en nuestro continente.

${ }^{14}$ Esta característica ha sido reconocida crecientemente por los Estados de la región, en especial ha sido recogida en la declaración final de la IV Conferencia de Ministros de Defensa de las Américas celebrada en la ciudad de Manaos, Brasil, 2000.

${ }^{15}$ No es ajeno a este rol de la ONU en los conflictos de la región la confluencia de dos elementos: por un lado, el marcado sesgo que la administración estadounidense asumió en tiempos de Guerra Fría (la era Reagan fue una de las paradigmáticas al respecto). Por otro, el interés de Europa por contribuir a distender los principales focos de conflicto de la Guerra Fría que la dejaban entrampada entre su pertenencia a la OTAN y la cercanía del Pacto de Varsovia. 


\section{EL IMPACTO \\ DEL 11 DE SEPTIEMBRE DEL 2001}

El estado de la cuestión tiene un antes y un después del atentado a las Torres Gemelas y al Pentágono.

$\mathrm{El}$ antes era muy sencillo. La mayoría de los países entendía que la institucionalidad vigente no estaba al día para responder a la problemática de la post Guerra Fría en el continente. Los mayores cuestionamientos se dirigían hacia el TIAR y, por añadidura, a la Junta Interamericana de Defensa. Se los catalogaba de ineficaces y, sobre todo, de responder a los diseños del enfrentamiento entre Estados Unidos y la Unión Soviética. Esto estaba de más, afirmaba, porque, entre otras cosas, la Unión Soviética ya no existía. En esa dirección surgió en la Segunda Cumbre Hemisférica la necesidad de convocar a una Conferencia Ad Hoc y constituyó una Comisión específica que trabajase el tema. En un paso de confianza a la OEA, se la colocó en su orgánica.

\section{EI TIAR demostró ser el único mecanismo vigente para viabilizar la solidaridad de los países de la región con Estados Unidos.}

Los cuestionamientos al TIAR abundaban al iniciarse el nuevo siglo en la re- gión. En la Conferencia de Manaos (2000), la delegación venezolana planteó una radical crítica al organismo y sugirió la necesidad de constituir una "OTAN bolivariana", que respondiese a los intereses de seguridad específicos de América Latina, tomando nota de los intereses globales que tienen los Estados Unidos. La idea predominante era el reconocimiento de la diversidad subregional que caracterizaba al continente en materia de problemáticas de seguridad y la constatación de la nueva institucionalidad emergente. En esos instantes, si bien los defensores a ultranza del TIAR no tenían muchos argumentos, invocaban el hecho cierto de que se trataba del único mecanismo de seguridad existente. Si se perfeccionaba en los nuevos tiempos de la post Guerra Fría, o si se reemplazaba por otro, sería tema de la futura Conferencia de Seguridad Hemisférica, se decía en esos momentos. En suma, si bien el TIAR no servía de mucho, tampoco molestaba demasiado como para apresurarse a reemplazarlo por otro cuyo cometido aún no estaba bien delineado.

Asimismo, desechada parcialmente la idea de concebir al narcotráfico como una nueva y homogénea amenaza para todos y cada uno de los países ${ }^{16}$, se concebía implícitamente que el realismo aconsejaba consolidar los mecanismos subregionales y avanzar hacia aproximaciones sucesivas entre ellos, a fin de ir configurando el nuevo sistema hemisférico.

${ }^{16}$ Una advertencia: la totalidad de los países reconocen que el narcotráfico es una amenaza de las más importantes, lo que se impugna es el darle un carácter homogéneo y, por ende, una solución única (que implique el uso de las FF.AA.). En algunos países el tema implica el uso de recursos militares, pero en la mayoría tiene que ver con dimensiones principalmente policiales, de control de la inversión -por el lavado de dinero- o de apoyo de inteligencia. 
Tal era la situación en septiembre del 2001. En la primera semana de dicho mes y dicho año, el presidente mexicano, Vicente Fox, en medio de una visita a los Estados Unidos, anunció oficialmente que México había resuelto denunciar el TIAR, por razones como las aquí enunciadas ${ }^{17}$. Simultáneamente, ofreció a su país como sede de la Conferencia de Seguridad Hemisférica, la cual en definitiva quedó convocada para mayo del presente año. México se ponía así a la vanguardia del conjunto de países de la región que habían venido adelantando opiniones sobre la necesidad de recomponer y repensar el sistema de seguridad vigente.

Los atentados terroristas cambiaron la situación.

En pocas horas, Brasil instó a los países a convocar al TIAR para apoyar a los Estados Unidos frente a la agresión que estaba sufriendo. El debate, además, se condimentó con la categórica afirmación del presidente Bush de que: "o se está con nosotros o contra nosotros". En las condiciones concretas inmediatamente posteriores al atentado, el TIAR mostró ser el único mecanismo vigente para viabilizar el TIAR nunca fue diseñado para las nuevas amenazas que representa el terrorismo global, ni menos Al Qaeda calza a plenitud con lo que se entiende por una "potencia extracontinental", lo cierto es que la convocatoria brasileña fue seguida por la unanimidad de los países de la región. La diplomacia mexicana sufría un traspiés.

\section{En materia de seguridad hay diversidad de intereses entre los países de la región, pero también amplias coincidencias.}

\section{A MODO DE CONCLUSIÓN}

Nos preguntábamos a inicios de este trabajo cuándo terminó la Guerra Fría en nuestra región. También nos interrogábamos respecto de si, desaparecido el conflicto bipolar, emergía una nueva amenaza, homogénea, desde Alaska hasta la Patagonia, que obligase a un mecanismo de seguridad colectiva de toda la región.

La Guerra Fría influyó en la región. De partida, ideologizó la mayoría de los conflictos existentes al interior de los diversos países de la región por un nuevo pacto social. En el caso centroamericano, lo que estrictamente tenemos allí es la explosión tardía de las movilizaciones antioligárquicas que en el resto del continente se dio entre el 1910 de la Revolución mexicana y el 1952 del MNR boliviano, pasando por la mayoría de los quiebres políticos en torno a la década de los treinta del siglo pasado. La alianza entre terratenientes (cafetaleros principalmente) y los gobiernos de excepción que predominó en el istmo fue cuestionada por las movilizaciones sociales de fines de la década de los setenta. La Guerra Fría

${ }^{17}$ En medio de una visita bilateral, México anunció la denuncia al TIAR y se ofreció para ser sede de la conferencia de Seguridad Hemisférica. Al mismo tiempo, Tlatelolco lograba colocar el complejo tema de la emigración en la agenda. Los Estados Unidos reconocían que México era su principal aliado. 
abanderizó a los bandos en pugna y de allí su fuerte ideologización, pero lo cierto es que concluidas las guerras, mediante los pactos democratizadores y republicanos se están construyendo nuevos esquemas sociales y políticos que no tienen nada que ver con la competencia por la hegemonía mundial.

En el caso sudamericano la situación es diferente. El fin de las dictaduras militares fue dando paso a una nueva fase de su historia política, de desigual resultado pero de comunes aspiraciones democráticas en lo político y aperturistas en lo económico. Quizás el caso chileno, por lo emblemático que fue, refleja con mayor nitidez ese proceso; por lo mismo, la polarización política propia del enfrentamiento bipolar, en Chile resaltó con toda su fuerza incluso en el período post ' 90 (es decir, una vez iniciada la transición chilena). En opinión del autor el eclipse del poder político del general Pinochet marca uno de los signos más inequívocos del fin de la Guerra Fría en el país, disolviéndose el eje bipolar (democracia-dictadura) que caracterizó la vida política chilena por más de dos décadas.

La Guerra Fría terminó. ¿Será posible reciclar el sistema de seguridad vigente al estilo del proceso que experimentó la OTAN en los años noventa? Es una interrogante abierta. Lo cierto es que, hoy en día, es posible advertir una diversificación muy amplia de intereses en materia de seguridad entre los diversos países ame- ricanos. Por su estatura estratégica y por sus diferentes estrategias de desarrollo.

Pero si bien es preciso reconocer esta diversidad, también existen amplias coincidencias. Una de las más importantes tiene que ver con la aspiración mayoritaria de los países americanos a consagrar formas democráticas en lo interno y apegadas al derecho internacional en lo que se refiere a la convivencia externa. Asimismo, con mayor o menor nivel de éxito y profundidad, la mayoría de los países del continente postula economías que apuestan a insertarse de mejor forma en la economía global. Son búsquedas no aislacionistas y cooperativas con los demás países de la región. Ello coloca a la estabilidad global, y por ende a la regional, en una condición básica para el éxito de esas estrategias de desarrollo. La paz regional, entonces, además de ser un valor compartido, pasa ser también un interés coincidente entre la mayoría de los Estados.

\section{El fin de las dictaduras dio paso}

\section{a una nueva escena política en Latinoamérica.}

El nuevo período histórico es generoso en mostrar las potencialidades de las nuevas amenazas, asimétricas y no necesariamente estatales (aunque sin duda requieren de bases locales, y si es con el apoyo de un Estado, mejor) ${ }^{18}$. El fenóme-

${ }^{18}$ Tal es el caso de Afganistán. El régimen talibán convivió y protegió a Al Qaeda, pero sería un error confundirlos plenamente. La derrota del mulah Omar no es necesariamente la neutralización de una organización descentralizada y transnacionalizada como lo es el ente que organizó Bin Laden. 
no del narcotráfico, que ya analizábamos, requiere en general de un tratamiento más policial que militar, al menos en la mayoría de los países americanos. Al mismo tiempo cabe preguntarse si en presencia de nuevas amenazas que se caracterizan por ser globales (y el terrorismo sin duda lo es), el Consejo de Seguridad de las Naciones Unidas no es el foro para organizar su combate y neutralización. Todos los países americanos coincidimos en que para enfrentar las nuevas amenazas es preciso fortalecer el tratamiento multilateral, el mejor escenario de cooperación para enfrentar estos flagelos. En ese caso, $i$ es necesario un régimen especial de seguridad colectiva en la región para atender amenazas de carácter global? Este trabajo no pretende dar respuesta a todas interrogantes; es más, sería presuntuoso el proponérselo. Se trata de procesos en pleno curso y su desenvolvimiento marcará el interés de la región en construir nuevos mecanismos que garanticen su estabilidad.
Lo que hemos querido -el lector dirá si lo conseguimos- es reseñar lo fundamental de la problemática en curso y resaltar que la diversidad de intereses de seguridad es la causa explicatoria de la denominada "arquitectura flexible" que hemos construido en estos años que, más allá de toda interpretación, ha transformado a la región en una de las zonas más estables del planeta terminada la Guerra Fría. Lo anterior no implica visiones idealistas ("se acabaron los conflictos...", "la democracia llegó para quedarse...", "se acabó la agenda tradicional...") como recurrentemente escuchamos, pero constata que la región se encuentra en mejores condiciones para construir un nuevo esquema de seguridad. Asimismo, desaparecido el esquema bipolar de análisis, la región (o sea América Latina y los Estados Unidos) ya no tienen entre sí diferencias mayores en temas de seguridad; por el contrario, comparten intereses y valores comunes: democaracia, liberalización económica, estabilidad global y regional. 